\title{
(MEMBUAT PROGRAM DATA RUMAH SAKIT DENGAN PEMOGRAMAN JAVA)
}

NPM $\quad: 19411064$

NAMA : ERIK BUDI PRASTIYO

PRODI : SISTEM INFPRMASI

FAKULTAS : KOMPUTER

EMAIL_: erikbudi002w@gmail.com

\section{SOAL TUGAS :}

1. Buatlah Program dengan ketentuan sebagai berikut :

Input :

kode pasien $=$ PS0003

Kode Kamar $=\mathbf{4 4 4 4 4}$

Lama Menginap $=5$ hari

Kode Dokter $=$ DK003

\begin{tabular}{|l|l|l|}
\hline Kode Pasien & Status Pasien & Biaya Daftar Pasien \\
\hline PS0001 & Pasien Baru & Rp. 500.000 \\
\hline PS0002 & Pasien Lama & Rp. 400.000 \\
\hline PS0003 & Pasien BPJS & Rp. 300.000 \\
\hline PS0004 & Pasien Askes & Rp. 200.000 \\
\hline
\end{tabular}

\begin{tabular}{|l|l|l|}
\hline Kode Kamar & Nama Kamar & Biaya Kamar \\
\hline 1111 & Kamar Melati & Rp. 1.000 .000 \\
\hline 2222 & Kamar Mawar & Rp. 2.000 .000 \\
\hline 3333 & Kamar Dahlia & Rp. 3.000.000 \\
\hline 4444 & Kamar Anggrek & Rp. 4.000.000 \\
\hline 5555 & Kamar Tulip & Rp. 5.000.000 \\
\hline
\end{tabular}




\begin{tabular}{|l|l|l|}
\hline Kode Dokter & Nama Dokter & Biaya Pemeriksaan \\
\hline DK001 & DR. Andi & Rp. 500.000 \\
\hline DK002 & DR. Joko & Rp. 400.000 \\
\hline DK003 & DR. Karni & Rp. 300.000 \\
\hline DK004 & DR. Amin & Rp. 200.000 \\
\hline DK005 & DR. Udin & Rp. 100.000 \\
\hline
\end{tabular}

\begin{tabular}{|l|l|}
\hline Lama Menginap & Diskon \\
\hline$>10$ Hari & $50 \%$ dari Biaya Kamar \\
\hline$>8$ Hari & $40 \%$ dari Biaya Kamar \\
\hline$>6$ Hari & $30 \%$ dari Biaya Kamar \\
\hline$>4$ Hari & $20 \%$ dari Biaya Kamar \\
\hline$>+1$ & $10 \%$ dari Biaya Kamar \\
\hline
\end{tabular}

public class datarumahsakit \{

public static void main (String[] args) \{

String kode_pasien = "PS003";

int kodekamar = 4444;

int lamamenginap = 5;

String kodedokter = "DK003";

String statuspasien, namakamar, namadokter;

double biayadaftarpasien,biayakamar, biayapemeriksaan,totalbayar,diskon;

if (kode_pasien.equals ("PSO01")) \{

statuspasien = "pasienbaru";

biayadaftarpasien $=500000$; 


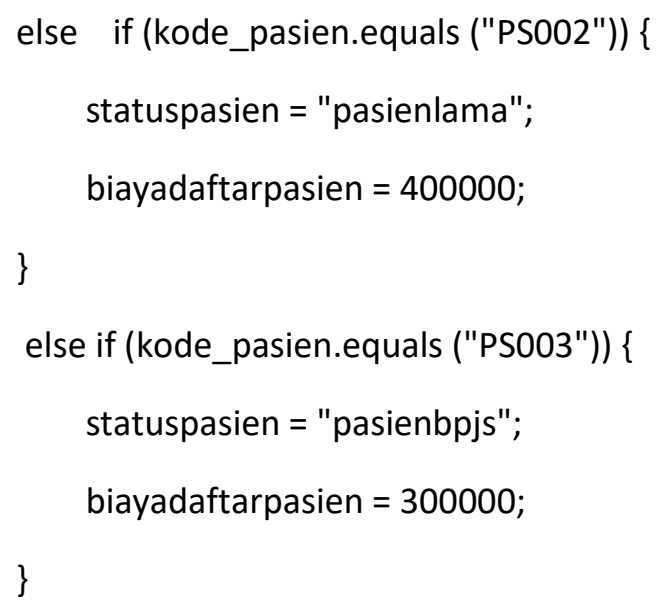




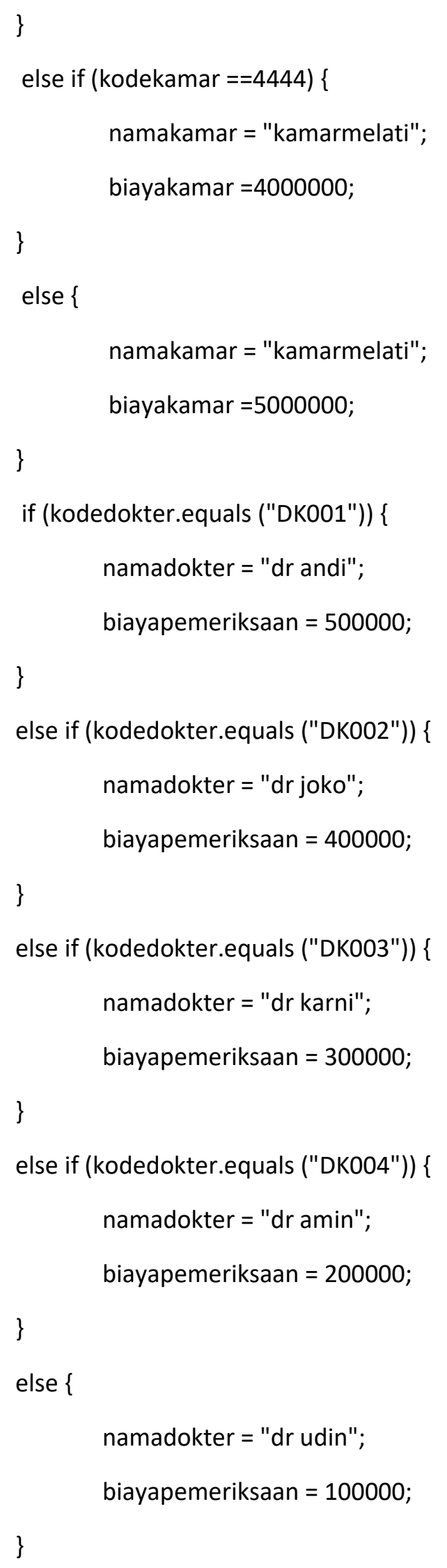




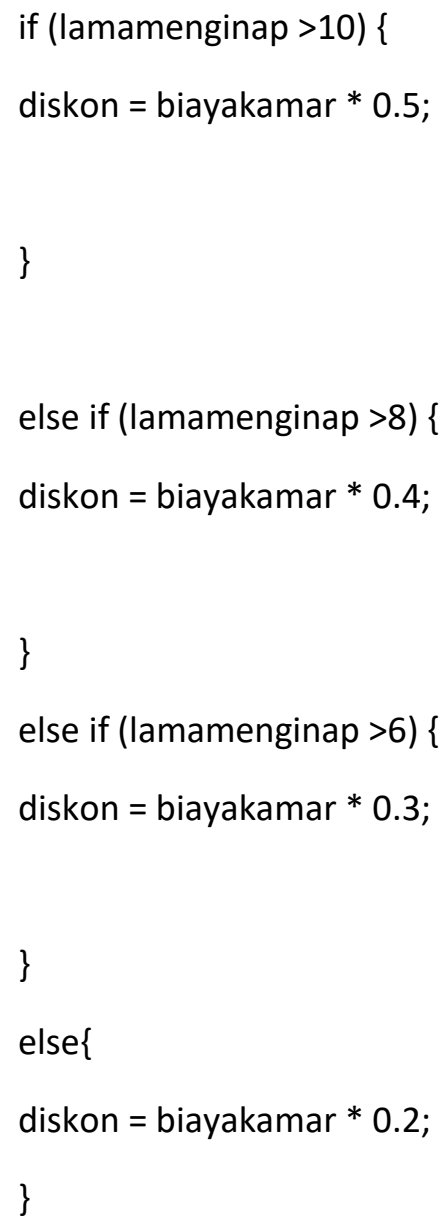

totalbayar= biayadaftarpasien+biayakamar+biayapemeriksaan-diskon;

System.out.println ("statuspasien" + statuspasien);

System.out.printIn ("biayadaftarpasien" + biayadaftarpasien);

System.out.println ("namakamar" + namakamar);

System.out.println ("biayakamar" + biayakamar);

System.out.printIn ("namadokter" + namadokter);

System.out.println ("biayapemeriksaan" + biayapemeriksaan);

\} 


\section{PENJELASAN}

Baris ke satu menyatakan bagian untuk mengawali pendefinisian kelas bernama pasien, kelas berubah suatu blok yang diawali dengan simbol \{ dan diakhiri dengan $\}$. Blok ini dimulai bagian baris pertama dan diakhiri pada baris akhir program. Kelas ini memiliki sebuah metode bernama main ( ). Main ( ) disebut dengan metode yang akan dijadikan sebagai awal pengeksekusikan dari aplikasi java, metode main ( ) didefinisikan sebagai publc static void menyatakan bahwa metode ini bisa dipanggil dari mana saja baik dari dalam maupun dari luar kelas bersifat sama untuk semua instan kelas berarti bahwa metode ini tidak memberikan nilai baik sebuah metode jika diperlikan dapat memberikan nilai baik.

kita menggunakan tanda (==) untuk menentukan persamaan pada suatu kondisi untuk menandakan nilai String.

Contoh : if (kodepasien=="PS0001")\{

Menentukan nilai data string

Kita menggunakan tanda ( [ ] ) digunakan untuk mengindikasikan sebuah larik atau array.

Contoh

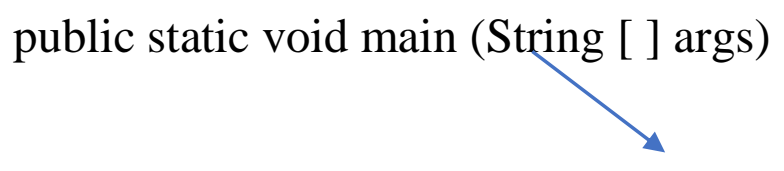

Tipe data String

Kita mengguanakan tanda ( \{\} ) digunakan untuk memulai dan mengakhiri sebuah program.

Contoh :

public class registrasi Pasien \{\}$\longrightarrow$ Garis kurawal Pemrograman Java 
Variabel String adalah tipe data untuk teks yang gabungan huruf, angka, spasi dan berbagai karakter.

Contoh :

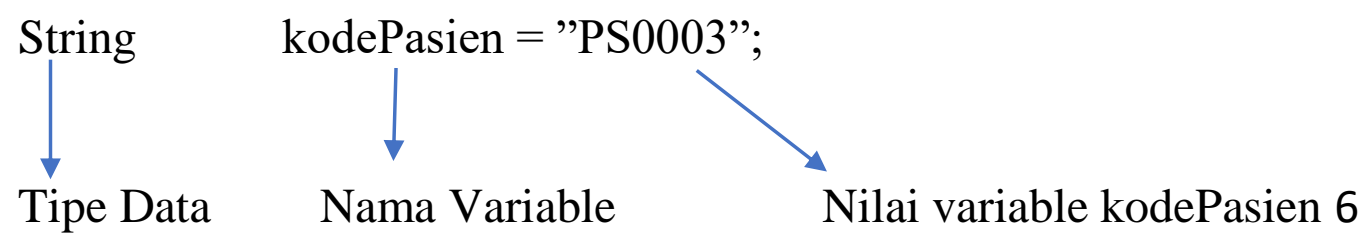


Variabel Double adalah variabel menggunakan angka sama seperti int tapi double dapat menggunakan koma dan tipe data.

Contoh :

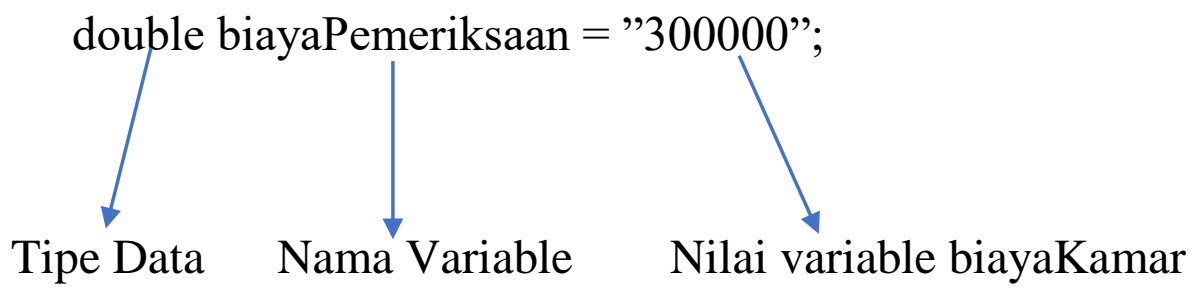

Kita mengguankan tanda (" ") digunakan untuk membentuk data String baik numeric atau alpha numeric yang berada diantara tanda sebagai String.

Contoh :

$$
\text { String kodePasien = "PS003"; } \longrightarrow \text { Variabel String }
$$

Percabangan majemuk (if else if) Percabangan majemuk merupakan bentuk opsi atau pilihan pernyataan terkondisi yang berguna untuk pengambilan keputusan terhadap banyak kemungkinan.

Contoh :

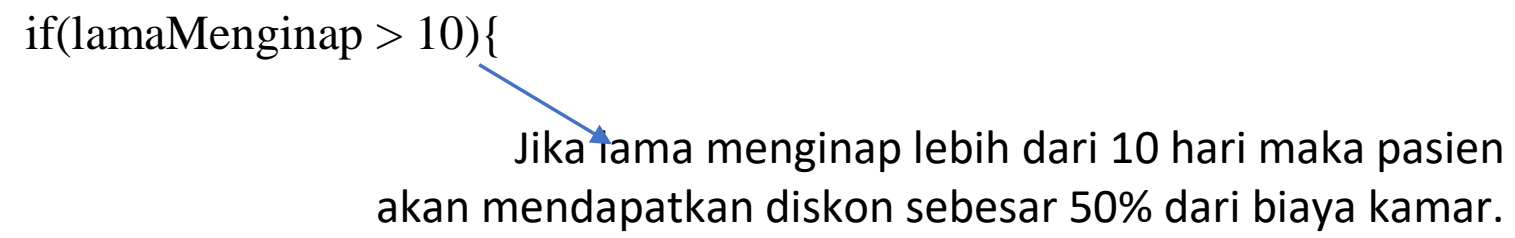

diskon $=$ biayaKamar*0.5;

\}else if(lamaMenginap > 8) \{

diskon = biayaKamar*0.4;

\}else if(lamaMenginap > 6) \{

diskon = biayaKamar*0.3;

\}else if(lamaMenginap > 4) \{

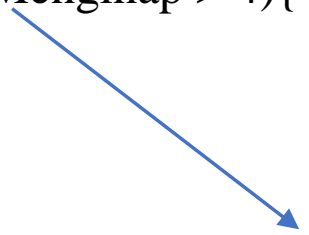

Dan jika nilai variable tidak memenuhi kondisi if pertama maka akan pindah ke operasi 
selanjutnya, begitupun seterusnya hingga berujung pada else.

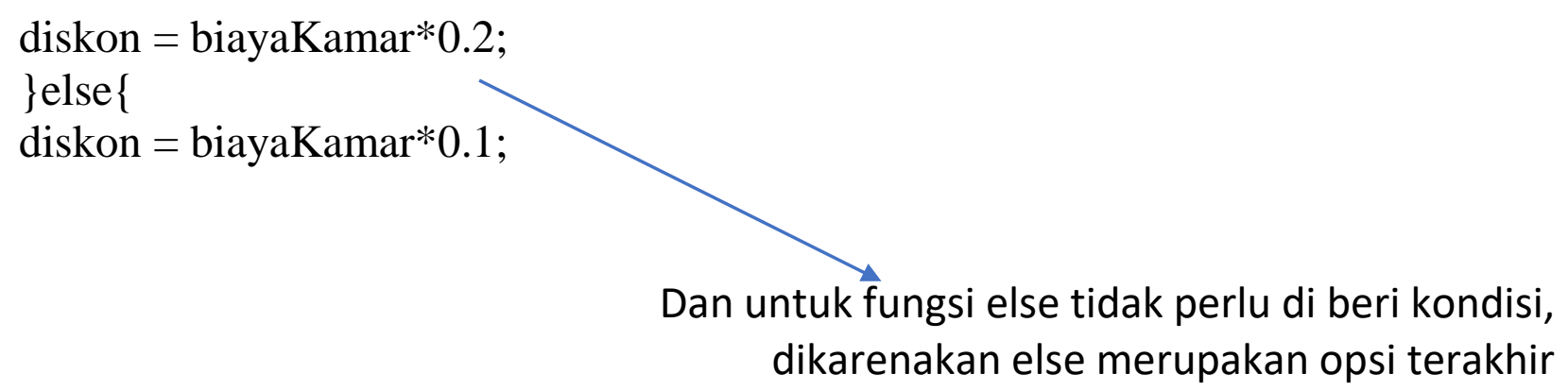


Operator aritmatika java adalah operasi matematika yang meliputi penjumlahan $(+)$,pengurangan (-) ,perkalian (*), pembagian (/) dan modulus (\%)(Sisa Hasil bagi).

Contoh :

double biayaDaftarPasien $=300000$;

double biayaKamar $=4000000$;

double biayaPemeriksaan $=300000$;

diskon = biayaKamar*0.2;

totalBayar = biayaDaftarPasien+biayaKamar+biayaPemeriksaan-diskon; Operasi Aritmatika Java

cara menampilkan ouput tulisan ke layar pada pemrograman java adalah dengan cara menggunakan perintah : System.out.println( $("="+)$;

Contoh :

System.out.println("Status Pasien="+statuspasien); System.out.println("Biaya Daftar Pasien="+biayadaftarpasien); System.out.println("Nama Kamar="+namakamar); System.out.println("Biaya Kamar ="+biayakamar); System.out.println("Nama Dokter="+namadokter); System.out.println("Biaya Pemeriksaan="+biayapemeriksaan); System.out.println("Diskon="+diskon); System.out.println("Total Bayar="+totalbayar);

klik Ctrl 1 bila Tool completed successfully itu di katakan berhasil sesuai di bawah ini ;

Klik Ctrl 2 untuk menampilkan hasil programan yang di input dari awal sampai akhir, di bawah ini hasil dari program pasien : 


\section{FLOWCHART PROGRAM}

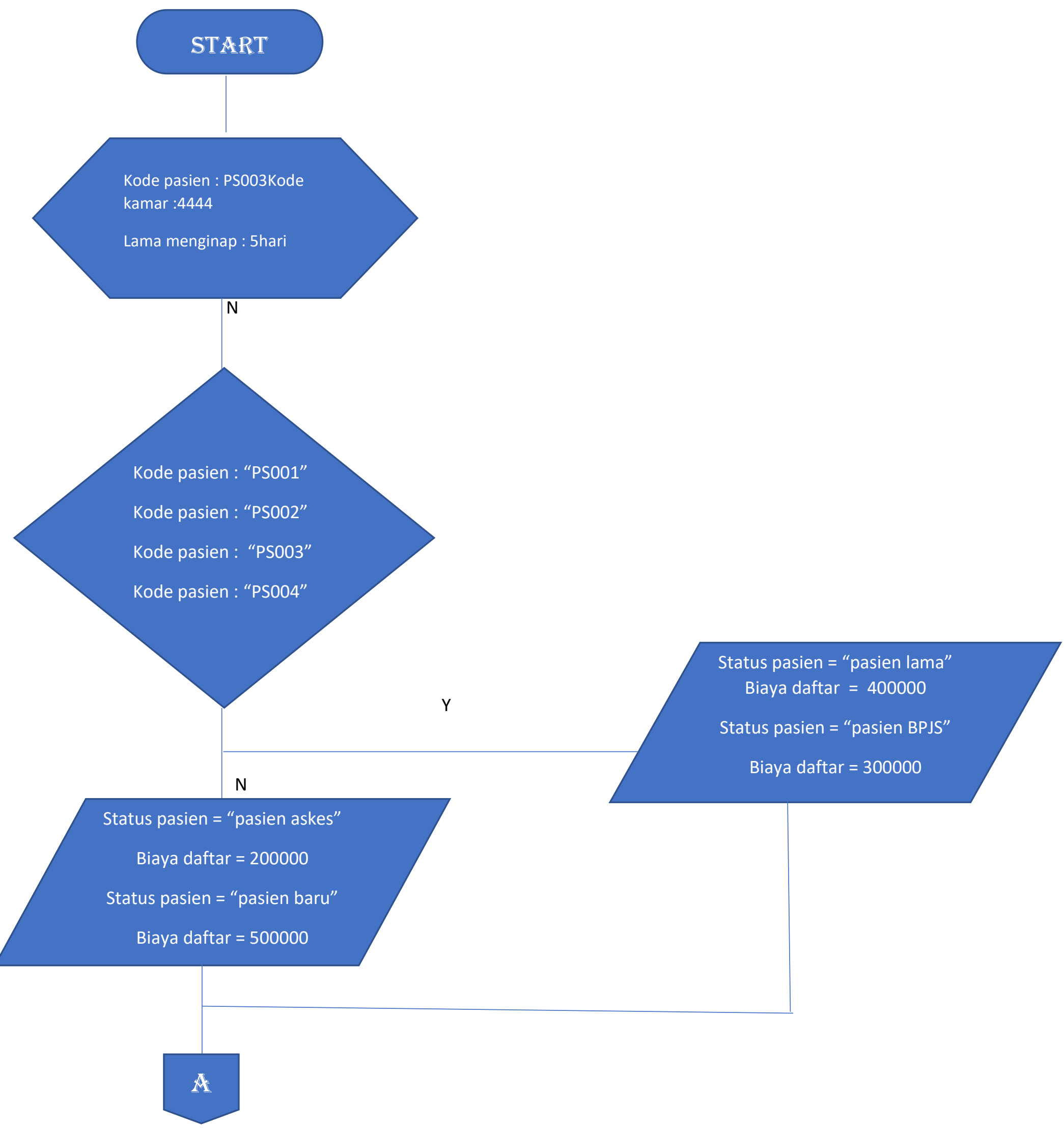


A

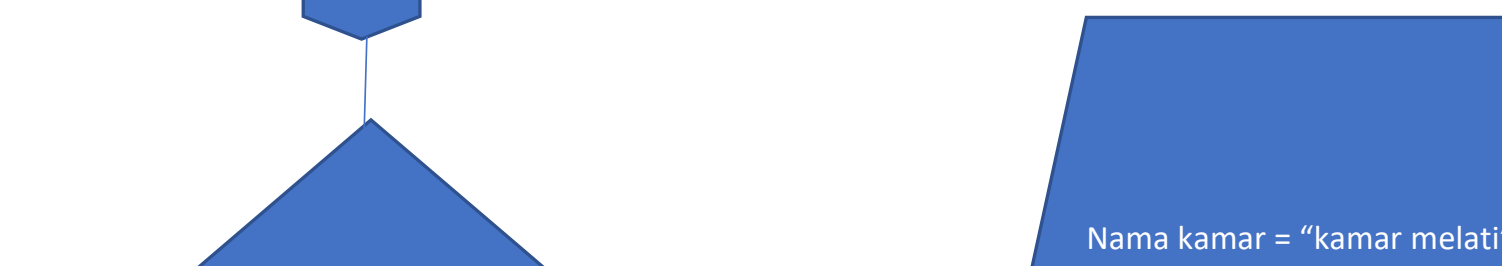

Biaya kamar =100000

Nama kamar = "kamar mawar"

Biaya daftar $=200000$

Nama kamar = "kamar dahlia”

Biaya daftar $=3000000$

Nama kamar = "kamar anggrek"

Biaya daftar $=4000000$

N

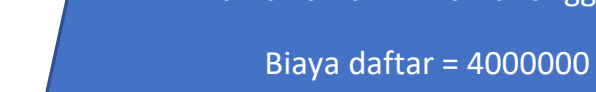

Nama kamar = "kamar tulip"

Biaya daftar $=5000000$

\section{B}




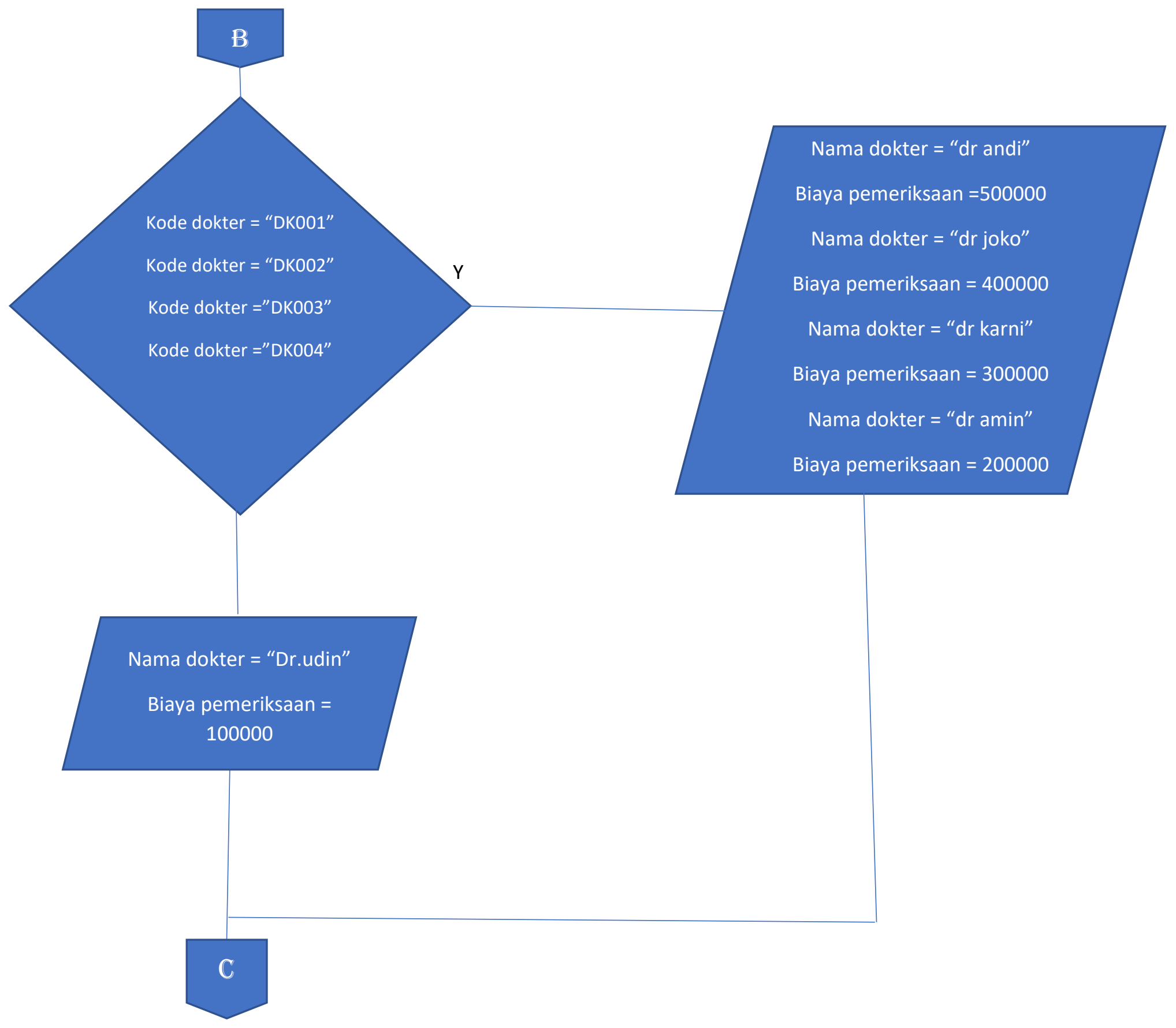




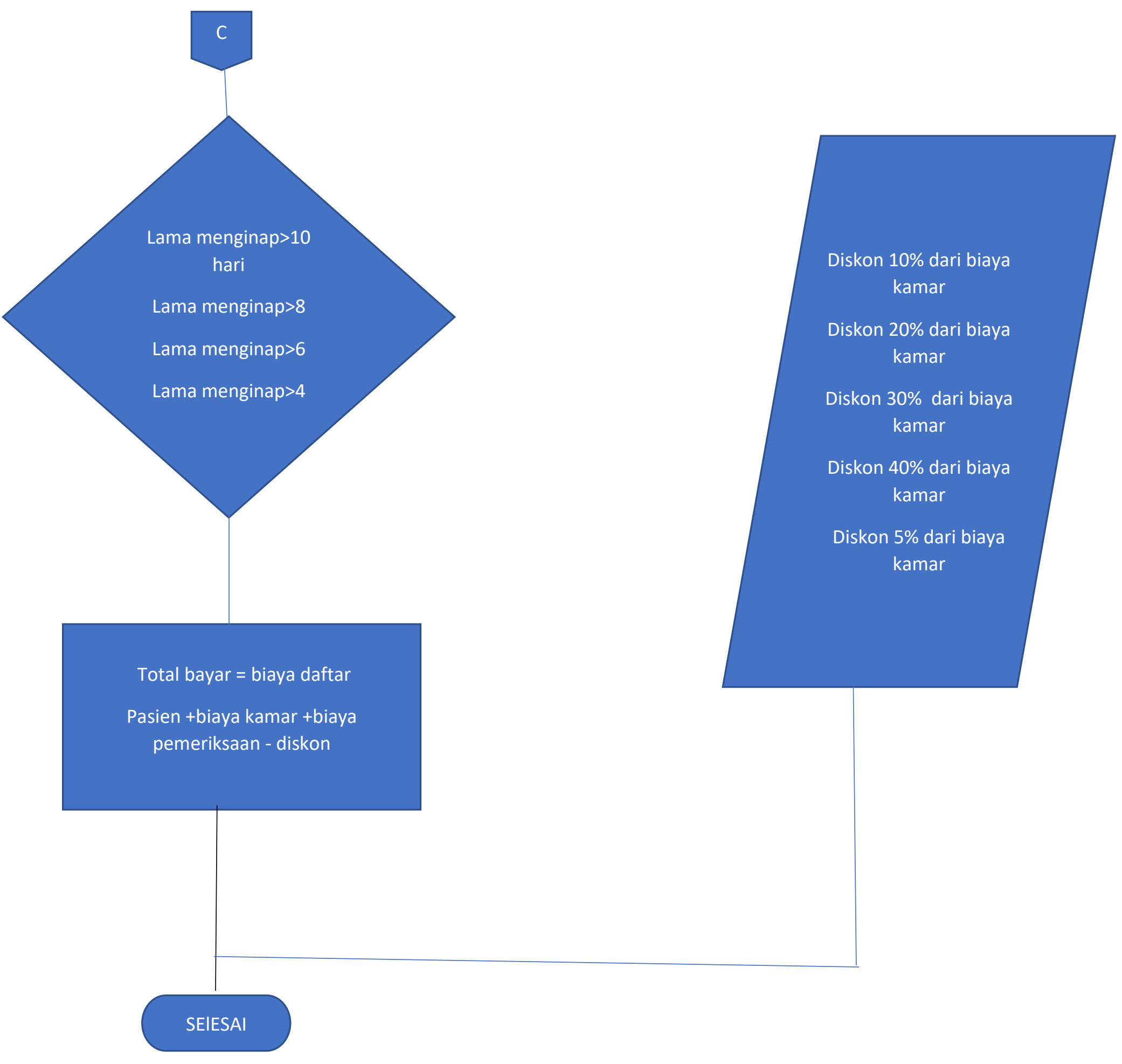




\section{REFERENSI :}

Endra, R. Y. (2019, October 29). Belajar Mudah Algoritma dan Pemograman Java. Retrieved from osf.io/v7yfn

Endra, R. Y. (2019, October 29). Internet of Things. Retrieved from osf.io/4h8sf 